\title{
Editorial
}

\section{Home Oxygen Therapy: The Jury is Still in Session}

\author{
Ann C. Halbower, MD \\ Sharon A. McGrath, MD
}

Journal of Perinatology (2004) 24, 59-61. doi:10.1038/sj.jp.7211030

In the last issue of The Journal of Perinatology (2004;24:36-40), Ellsbury and colleagues ask a controversial question about oxygen therapy for infants with chronic lung disease: Just how much is appropriate and which infants should be treated? After polling the Vermont 0xford Network participants, the authors report that 43\% of those responding would not choose to initiate home oxygen therapy in discharged preterm infants until oxygen saturations were less than $90 \%$. Furthermore, once home oxygen therapy was initiated, oxygen saturation levels targeted by respondents varied between $>84$ and $>98 \%$. Even if there was no variability in treatment regimens of the infant in neonatal units, this article demonstrates that target oxygen saturation goals for the preterm headed home are very disparate. This discrepancy alone could potentially result in very different outcomes for graduates of neonatal units. The findings of Ellsbury et al. underscore the need to assess what we know about the risks and benefits of oxygen therapy for the former preterm graduate of the neonatal unit. However, it is equally important to focus on the limitations of the available data in order to determine the goals of future research efforts.

A large percentage of the Vermont Oxford Network participants chose to reserve oxygen therapy for infants with oxygen saturations less than $90 \%$, and for many, the initiation level was less than $88 \%$. There may be some reluctance to consider an infant now "oxygen dependent" when prior saturation goals immediately after birth were lower due to the increased risk of retinal disease. ${ }^{1,2}$ Recent controlled trials might lead the practitioner to keep oxygen saturation goals low permanently, if cautious interpretation of those studies is not performed. For instance, in the Australian "BOOST" trial (Benefits of Oxygen Saturation Targeting), ${ }^{3}$ there were patients in a low oxygen saturation group (91 to 94\% targets) and a high saturation group (95 to 98\%) with no significant outcome differences in growth or major developmental handicaps. Patients in both experimental arms were sent home on oxygen

Johns Hopkins Hospital Department of Pediatrics, Pediatric Pulmonology, Baltimore, USA; Euloweod Division of Pediatric Respiratory Sciences, John Hopkins University, Baltimore, Maryland, USA. with saturation targets of greater than or equal to $91 \%$. The effect of oxygen saturation levels below $91 \%$ on long-term growth or development cannot therefore be inferred from that study.

The former premature 2-month-old infant now has a new disease compared to the same infant at birth. Due to cancelled fetal growth, combined with development that has altered its trajectory, the disease risks and profiles for the ex-premature infant are dramatically different. Diminished lung volumes cause dramatic ventilation/perfusion mismatches with simple colds. Infants with bronchopulmonary dysplasia have unexpected episodes of significant oxygen saturation reductions while sleeping or feeding. ${ }^{4}$ We are now faced with critical questions concerning proper oxygen saturation targets for these former premature infants. What saturation level should be targeted to meet respiratory and cognitive requirements while not compromising tissue development? Should oxygen saturation goals be increased in the older developing preterm graduate of the neonatal unit?

There may be significant risks to oxygen therapy as outlined below. Unfortunately, the threshold oxygen saturation that increases each risk is unknown. As demonstrated in animal studies, possible permanent blunting of ventilatory responses to hypoxia develops after exposure to high oxygen saturations at a critical developmental period. ${ }^{5,6}$ Theoretical problems resulting from a blunted response could lead to increased sleep disordered breathing, hypoxia with illness, or could contribute to a risk of death. The existence of this critical period, or its age of occurrence, in humans remains to be determined. Infants on high oxygen levels (target saturation $=95$ to $99 \%$ ) in the controlled "STOPROP" trial, which followed 649 preterm infants after 35 weeks postmenstrual age, demonstrated some retinal benefits after the development of the second phase of retinopathy of prematurity (ROP). On the down side, there was an increased incidence of pulmonary issues in that group compared to the lower oxygen target. In contrast, the B00ST trial that had an upper limit cutoff of $98 \%$ in the high oxygen saturation group did not see significant abnormal pulmonary outcomes in the two treatment arms.

The preterm infant, cut off from protective placental factors, may demonstrate specific regulatory abnormalities of tissue development when exposed to the toxicity of hyperoxia. ${ }^{8}$ For example, the mechanism proposed for hyperoxia-induced tissue 
alteration in the retina includes the downregulation of vascular endothelial growth factor during initial blood vessel formation. ${ }^{9}$ Causes for lung arrest and remodeling in hyperoxic conditions may involve the induction of cell cycle inhibitors, ${ }^{10}$ and cytokines, ${ }^{11}$ combined with decreased levels of antioxidants in the premature infant. ${ }^{12}$ The discovery of common pathways for the development of alveolar injury in bronchopulmonary dysplasia, ROP, and even emphysema ${ }^{13}$ may lead to common therapies in the near future, but the necessity to put an upper limit on the oxygen saturation target, and to define the age of tissue vulnerability to oxygen is underscored. This age of vulnerability may have been early in the initial exposure to room air in the neonatal unit.

The STOP-ROP and BOOST trials suggest that lower oxygen saturation targets may be of benefit, at least in terms of the burden of home oxygen therapy. However, the safe lower limit of oxygen saturation has not been determined, specifically in terms of neurocognitive development. These trials leave off where our questions begin. In early childhood development, significant gains in cognitive function are achieved, such as executive functions related to ongoing myelination of the frontal systems. ${ }^{14}$ Infants with cerebral impairments are frequently diagnosed only after their first year of age when neuropsychological testing allows a more subtle assessment of achievement. A score of more than two standard deviations below the mean on a mental development scale at the age of 1 year was used to define "developmental abnormality" in the BOOST trial. This is just the first crude step in assessing the cerebral impact of hypoxia or hyperoxia in infants. Intermittent oxygen desaturation is known to cause significant learning deficits in animal studies. ${ }^{15}$ Hypoxic events can leave permanent damage in areas of the brain known to be sensitive to hypoxia, such as the cerebellum, thalamus and hippocampus. ${ }^{16,17}$ Hypoxic and arousal events during sleep apnea in children have been associated with deficits of learning and memory. ${ }^{18}$ Decreased pulmonary reserve in infants born prematurely can lead to decreased oxygen saturation during sleep, ${ }^{4}$ which is rarely taken into account during daytime pulse oximetry checks. Should we consider the developing infant brain to have more resistance to hypoxia than that of the older child, or should normal oxygen saturations be targeted?

Authors of the BOOST trial have suggested that the outcome of home oxygen use for the discharged premature infant is an increased burden on health services. Although not clearly stated, one might interpret that the authors of the study were alluding to the financial or resource impact of oxygen therapy. The oxygen therapy burden might be considered a minor if not insignificant outcome in the United States in the light of the large number of medically and mentally handicapped children produced from premature deliveries. In fact, our improved neonatal care has turned a previously fatal disorder into a very expensive chronic illness. ${ }^{19}$
A consensus for the optimal oxygen saturation target in infants with chronic lung disease is essential. Future research efforts should emphasize oxygen saturation goals that optimize neurocognitive development while simultaneously avoiding collateral damage to vulnerable organs. Determining factors that prevent the toxicity of oxygen therapy will be critical for the treatment of all infants and children. The cerebral impacts of intermittent or chronic hypoxia require very close scrutiny because the outcome of mental handicaps so powerfully influence the longterm potential of an individual. If these efforts lead to improved (even subtle) neurodevelopmental outcomes in former premature infants, the cost to the health system is justified.

\section{References}

1. Patz A, Hoeck LE, De La Cruz. Studies on the effect of high oxygen administration in retrolental fibroplasia. I. Nursery observations. Am J Ophthalmol 1952;35:1248-53.

2. Tin W, Wariyar U. Giving small babies oxygen: 50 years of uncertainty. Semin Neonatol 2002;7:361-7.

3. Askie LM, Henderson-Smart DJ, Irwig L, Simpson JM. Oxygen-saturation targets and outcomes in extremely preterm infants. $\mathrm{N}$ Engl $\mathrm{J}$ Med 2003;349:959-67.

4. Garg M, Kurzner SI, Bautista DB, Keens TG. Clinically unsuspected hypoxia during sleep and feeding in infants with bronchopulmonary dysplasia. Pediatrics 1988;81:635-42.

5. Carroll JL. Developmental plasticity in respiratory control. J Appl Physiol 2003;94:375-89.

6. Bavis RW, Olson Jr. EB, Mitchell GS. Critical developmental period for hyperoxia-induced blunting of hypoxic phrenic responses in rats. J Appl Physiol 2002;92:1013-18.

7. Supplemental therapeutic oxygen for prethreshold retinopathy of prematurity (STOP-ROP), a randomized, controlled trial. I: primary outcomes. Pediatrics 2000;105:295-310.

8. Shih SC, Ju M, Liu N, Smith LE. Selective stimulation of VEGFR-1 prevents oxygen-induced retinal vascular degeneration in retinopathy of prematurity. J Clin Invest 2003;112:50-7.

9. Pierce EA, Avery RL, Foley ED, Aiello LP, Smith LE. Vascular endothelial growth factor/vascular permeability factor expression in a mouse model of retinal neovascularization. Proc Natl Acad Sci USA 1995;92:905-9.

10. McGrath SA. Induction of p21WAF/CIP1 during hyperoxia. Am J Respir Cell Mol Biol 1998;18:179-87.

11. Barazzone C, White CW. Mechanisms of cell injury and death in hyperoxia: role of cytokines and Bcl-2 family proteins. Am J Respir Cell Mol Biol 2000;22:517-9

12. Ochoa JJ, Ramirez-Tortosa MC, Quiles JL, et al. Oxidative stress in erythrocytes from premature and full-term infants during their first $72 \mathrm{~h}$ of life. Free Radic Res 2003;37:317-22.

13. Tuder RM, Zhen L, Cho CY, et al. Oxidative stress and apoptosis interact and cause emphysema due to vascular endothelial growth factor receptor blockade. Am J Respir Cell Mol Biol 2003;29:88-97.

14. Welch MC, Pennington BF, Groisser DB. A normative-developmental study of executive function. A window on prefrontal function in children. Dev Neuropsychol 1991;7:131-49. 
15. Row BW, Kheirandish L, Neville J, Gozal D. Impaired spatial learning and hyperactivity in developing rats exposed to intermittent hypoxia. Pediatr Res 2002;52:449-53.

16. Cervos-Navarro J, Diemer NH. Selective vulnerability in brain hypoxia. Crit Rev Neurobiol 1991;6:149-82.

17. Higuchi T, Graham SH, Fernandez EJ, et al. Effects of severe global ischemia on $N$-acetylaspartate and other metabolites in the rat brain. Magn Reson Med 1997;37:851-7.
18. Rhodes SK, Shimoda KC, et al. Neurocognitive deficits in morbidly obese children with obstructive sleep apnea. J Pediatr 1995;127:741-4.

19. May W, Rice DP, Trupin L, et al. Medical expenditures for people with disabilities in the US, Disability Statistics Report \#5, Institute for Health and Aging at the UCSF, 1995, (http://nurseweb.ucsfedu/iha/) 